\title{
Experience-Dependent Emergence of Fine-Scale Networks in Visual Cortex
}

\author{
Ayako Wendy Ishikawa, ${ }^{1}$ Yukio Komatsu, ${ }^{2}$ and Yumiko Yoshimura ${ }^{1,2,3,4}$ \\ ${ }^{1}$ Division of Visual Information Processing, National Institute for Physiological Sciences, National Institutes for Natural Sciences, Okazaki 444-8585, Japan, \\ ${ }^{2}$ Department of Neuroscience, Research Institute of Environmental Medicine, Nagoya University, Nagoya 464-8601, Japan, ${ }^{3}$ Department of Physiological \\ Sciences, The Graduate University for Advanced Studies, Okazaki 444-8585, Japan, and ${ }^{4}$ Precursory Research for Embryonic Science and Technology, Japan \\ Science and Technology Agency, Saitama 332-0012, Japan
}

Visual cortical neurons selectively respond to particular features of visual stimuli and this selective responsiveness emerges from specific connectivity in the cortex. Most visual response properties are basically established by eye opening and are thereafter modified or refined by visual experience based on activity-dependent synaptic modifications during an early postnatal period. Visual deprivation during this period impairs development of visual functions, such as visual acuity. We previously demonstrated that fine-scale networks composed of a population of interconnected layer $2 / 3(\mathrm{~L} 2 / 3)$ pyramidal neurons receiving common inputs from adjacent neurons are embedded in a small area in rat visual cortex. We suggested that this network could be a functional unit for visual information processing. In this study, we investigated the effects of early visual experience on the development of fine-scale networks and individual synaptic connections in rat visual cortical slices. We used two kinds of deprivation, binocular deprivation and dark rearing, which allowed visual inputs with only diffuse light and no visual input, respectively. The probability and strength of excitatory connections to L2/3 pyramidal cells increased during the 2 weeks after eye opening, and these changes were prevented by dark rearing, but not binocular deprivation. Fine-scale networks were absent just after eye opening and established during the following 2 weeks in rats reared with normal visual experience, but not with either type of deprivation. These results indicate that patterned vision is required for the emergence of the fine-scale network, whereas diffuse light stimulation is sufficient for the maturation of individual synapses.

Key words: fine-scale network; patterned vision; photostimulation; synaptic connection; visual cortex; visual deprivation

\section{Introduction}

Sensory cortical neurons of mammals selectively respond to particular stimulus features and this selective responsiveness is believed to emerge from specific connectivity in the cortex (Hubel, 1982). In visual cortex, while most visual response properties are basically established by eye opening, they are thereafter modified or refined by visual experience during an early postnatal period (Wiesel, 1982; Frégnac and Imbert, 1984; Chapman and Stryker, 1993; Chapman et al., 1996; Gödecke and Bonhoeffer, 1996; Crair et al., 1998; White et al., 2001; Huberman et al., 2008). During development, response selectivity is usually degraded, to an extent depending on the duration of deprivation, by binocular deprivation or dark rearing (Frégnac and Imbert, 1984; Crair et al., 1998; White et al., 2001), which allows visual inputs with only

\footnotetext{
Received April 3, 2014; revised Aug. 4, 2014; accepted Aug. 8, 2014.

Author contributions: A.W.I., Y.K., and Y.Y. designed research; A.W.I. and Y.Y. performed research; A.W.I. and Y.Y. analyzed data; A.W.I., Y.K., and Y.Y. wrote the paper.

This work was supported by the Funding Program for Next Generation World-Leading Researchers (LS137 to Y.Y.) and Grant-in-Aids for Scientific Research on Innovative Areas (\#22115007 to Y.Y. and \#23110004 to Y.K.), Ministry of Education, Culture, Sports, Science, and Technology, Japan. We thank T. Watabe and T. Sato for their technical assistance in developing the photostimulation system.

The authors declare no competing financial interests.

Correspondence should be addressed to Yumiko Yoshimura, Division of Visual Information Processing, National Institute for Physiological Sciences, 0kazaki 444-8585, Japan. E-mail: yumikoy@nips.ac.jp.

DOI:10.1523/JNEUROSCI.1346-14.2014

Copyright $\odot 2014$ the authors $\quad 0270-6474 / 14 / 3312576-11 \$ 15.00 / 0$
}

diffuse light or no visual input, respectively (Crawford and Marc, 1976; Loop and Sherman, 1977; Spear et al., 1978). Behavioral studies using rodents have demonstrated that visual acuity steeply develops during the first 2 weeks after eye opening and that dark rearing and binocular deprivation both impair this development (Prusky et al., 2000, 2004; Kang et al., 2013). Binocular matching of orientation preference in individual visual cortical neurons takes place during this period (Wang et al., 2010). It is assumed that activity-dependent synaptic modifications underlie these experience-dependent alterations of visual functions (Bear et al., 1987; Singer, 1995; Katz and Shatz, 1996; Zhang and Poo, 2001). However, many questions related to the changes in synaptic connections that underlie this developmental process still remain unresolved.

We previously demonstrated that multiple fine-scale networks of precisely interconnected excitatory neurons were embedded in a small area in rat visual cortex. We suggested that these networks could be functional units for visual information processing (Yoshimura et al., 2005). Other studies have supported the presence of this kind of microcircuit in the neocortex (Song et al., 2005; Perin et al., 2011). These fine-scale networks include two types of essential neuronal elements. One is a group of adjacent layer 2/3 (L2/3) pyramidal cells, each of which has synaptic connections with $\geq 1$ cell, but usually $>1$ cell, belonging to the group. The other is a group of L2/3 and L4 cells sending common 
A
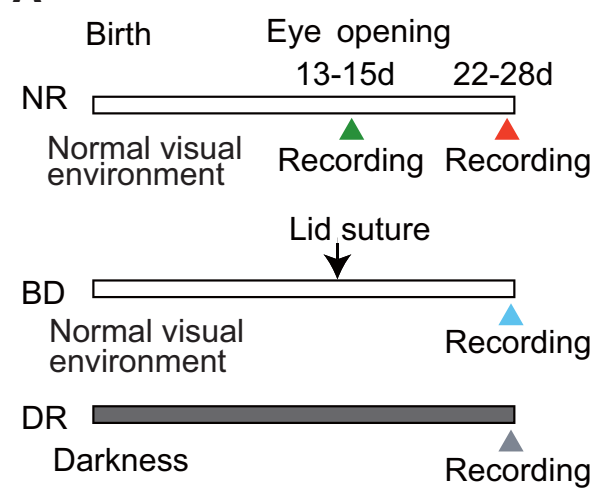

B

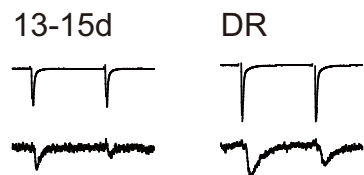

C

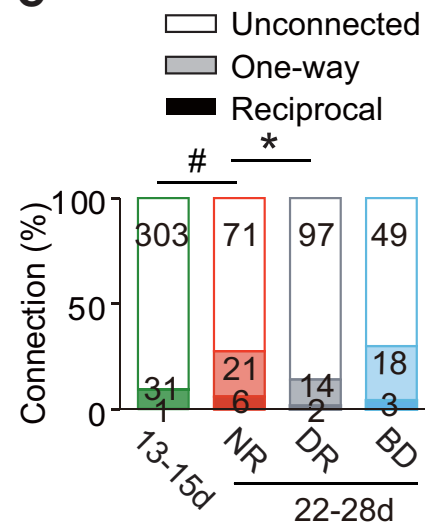

D

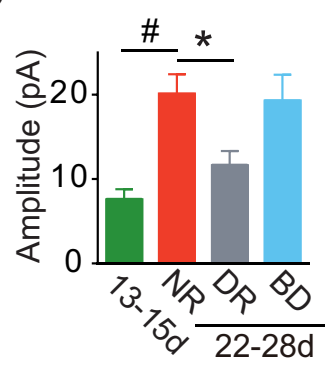

H

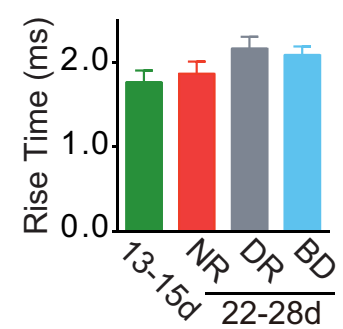

E

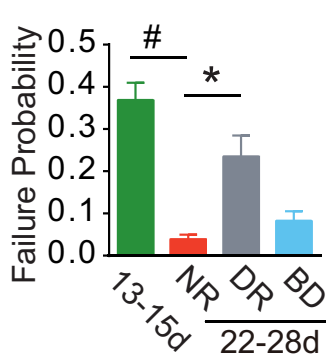

I

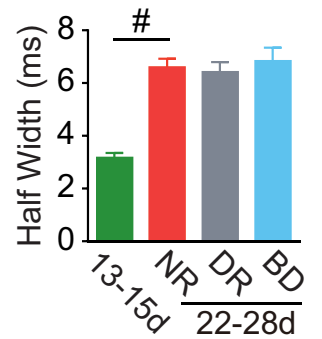

F

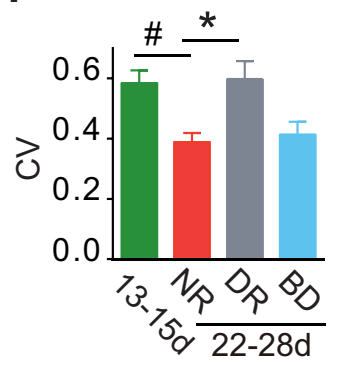

J

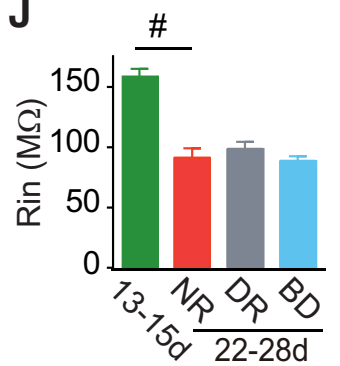

G

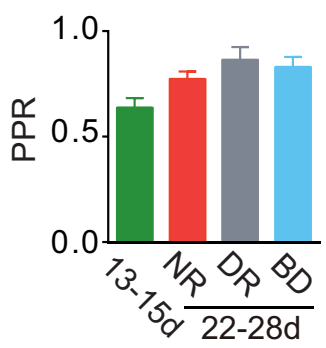

K

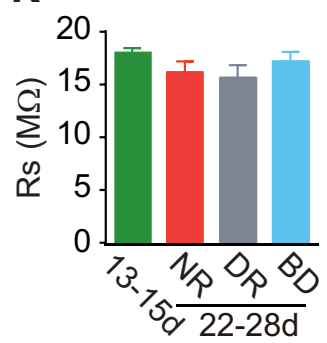

Figure 1. Experimental schedule and development of unitary EPSCs between adjacent L2/3 pyramidal cell pairs. $A$, Manipulation of visual experience and timeline of the experiments. Recordings were obtained from rats just after eye opening [P13-P15 (13-15d)], and from 3-week-old rats [P22-P28 (22-28d)] reared normally (NR), with binocular deprivation (BD), and in darkness (DR). B, Example average $(n=8)$ traces of presynaptic action currents evoked by depolarizing voltage pulses (top) and resultant EPSCs (bottom), which were obtained from cell pairs in each of the experimental groups. Calibrations are common to all traces. C, Percentage of cell pairs that were connected in both directions (dark bar), in one direction (light bar), or not connected (blank bar). The numbers of cell pairs are indicated in the bars. $\chi^{2}$ Test; \#p $<0.05$ between normal rats at P13-P15 (13-15d) and P22-P28 (22-28d), and * $p<0.05$ versus normal rats (comparison between the 3-week-old groups). $\boldsymbol{D}-\boldsymbol{I}, \mathrm{A}$ bar graph shows the value (mean \pm SEM) of amplitude $(\boldsymbol{D})$, failure probability $(\boldsymbol{E}), \mathrm{CV}(\boldsymbol{F}), \mathrm{PPR}(\boldsymbol{G}), 10-90 \%$ rise time $(\boldsymbol{H})$, and half-width $(\boldsymbol{I})$ of unitary EPSCS recorded from connected pairs. In $\boldsymbol{A}$, the amplitude of EPSCs was averaged for all of the stimulation trials, including those that resulted in transmission failure. $\boldsymbol{J}-\boldsymbol{K}$, Input resistance (J, Rin) and series resistance $(\boldsymbol{K}, \mathrm{Rs})$ of postsynaptic cells. In $\boldsymbol{D}-\boldsymbol{K}$, the number of cell pairs was 32 (13-15d), 27 (NR), 16 (DR), and 21 (BD). Mann-Whitney test; \#p < 0.05 between normal rats at P13-P15 (13-15d) and P22-P28 (22-28d). Dunn's test; ${ }^{*} p<0.05$ versus normal rats (comparison between the 3-week-old groups).

excitatory inputs to connected L2/3 pyramidal cell pairs belonging to the first group (Yoshimura et al., 2005).

In this study, we investigated the effects of early visual experience on the development of individual synaptic connections and fine-scale networks in rat visual cortex. The probability and strength of synaptic connections to L2/3 pyramidal cells increased during the 2 weeks after eye opening, and these changes were prevented by dark rearing, but not binocular deprivation. These fine-scale networks were absent just after eye opening and established during the following 2 weeks in rats reared with normal visual experience, but not with either type of deprivation. These results indicate that patterned vision is required for the emergence of a fine-scale network, while diffuse light stimulation is sufficient for the maturation of individual synaptic connections.

\section{Materials and Methods}

All of the experiments were performed under a protocol approved by the Experimental Animal Committee of Research Institute of Environmental Medicine, Nagoya University, and National Institute for Physiological Sciences.

Animals and slice preparations. Pigmented (Long-Evans) rats of either sex were reared in a normal visual environment ( $12 \mathrm{~h}$ light/dark cycles) or in complete darkness from birth. To remove patterned visual input, rats were subjected to binocular lid suture at postnatal day 12-13 (P12-P13), just before eye opening, under anesthesia with 3\% isoflurane. As described previously (Yoshimura et al., 2003), coronal slices $(300 \mu \mathrm{m})$ of primary visual cortex were prepared from 3-week-old (P22-P28) rats, which were reared normally, in darkness, or with binocular deprivation, under deep anesthesia with isoflurane. We also used slices prepared from rats just after eye opening (P13-P15). The slices were recovered for $1 \mathrm{~h}$ in oxygenated $\left(95 \% \mathrm{O}_{2}\right.$ and $\left.5 \% \mathrm{CO}_{2}\right)$ artificial CSF (ACSF) containing the 
following (in $\mathrm{mm}$ ): $126 \mathrm{NaCl}, 5 \mathrm{KCl}, 1.2$ $\mathrm{KH}_{2} \mathrm{PO}_{4}, 1.3 \mathrm{MgSO}_{4}, 3.2 \mathrm{CaCl}_{2}, 26 \mathrm{NaHCO}_{3}$, and 10 glucose at $33^{\circ} \mathrm{C}$. The slices were then kept in the ACSF at room temperature. During recording experiments, we perfused slices obtained from rats at the age of 3 weeks and P13-P15 with ACSF containing 4-Methoxy-7nitroindolinyl (MNI)-caged glutamate (100 $\mu \mathrm{M})$ and RuBi-caged glutamate $(80 \mu \mathrm{M})$, respectively, at room temperature. We used a modified ACSF, in which $\mathrm{Ca}^{2+}$ was replaced with $\mathrm{Sr}^{2+}$, for the analysis of quantal EPSCs.

Whole-cell recordings. An infrared Olympus differential interference contrast microscope with a X40, 0.8 numerical aperture (NA) water-immersion lens was used to visualize and target L2/3 pyramidal neurons for whole-cell recordings. When whole-cell recordings were performed from pairs of $\mathrm{L} 2 / 3$ pyramidal neurons, their somata were separated by $<50 \mu \mathrm{m}$. Cell bodies of the recorded neurons were located $\geq 50 \mu \mathrm{m}$ below the cut surface of the slice. Patch pipettes (4-6 M $\Omega$ ) were filled with an internal solution containing the following (in $\mathrm{mm}$ ): $130 \mathrm{~K}$-gluconate, $8 \mathrm{KCl}, 1 \mathrm{MgCl}_{2}$, 0.6 EGTA, 10 HEPES, $3 \mathrm{Na}-$

ATP, $0.5 \mathrm{Na}$-GTP, $10 \mathrm{Na}$-phosphocreatine, and $0.3 \%$ biocytin, $\mathrm{pH} 7.3$ adjusted with $\mathrm{KOH}$. The membrane potential of recorded cells was held at the reversal potential of IPSCs $(-70 \mathrm{mV})$. We selected cells with series resistance $<25 \mathrm{M} \Omega$ for analysis and did not use series resistance compensation. In all paired recordings, the connections between neuron pairs were assessed in both directions by applying pairs of brief (1-2 ms) depolarizing voltage pulses at an interval of 50 $\mathrm{ms}$ ( $\geq 50$ trials) to evoke action potentials in one of the cells and recording EPSCs from the other cell.

Photostimulation. Photostimulation was achieved by focal photolysis of MNI-caged glutamate with $10 \mathrm{~ms}$ flashes of ultraviolet light (355 nm) from a diode-pumped, solid-state laser in slices obtained at 3 weeks and focal photolysis of RuBi-caged glutamate with $3 \mathrm{~ms}$ flashes of blue light $(440 \mathrm{~nm})$ from a diode laser in slices obtained at P13-P15. The light was focused on the slices through an X4, 0.16 NA microscope objective and the diameter of the light beam was $\sim 20 \mu \mathrm{m}$ on the surface of slices. Laser power was set to $5 \mathrm{~mW}$ at the specimen plane. This resulted in the generation of action potentials in neurons with cell bodies mostly within $\sim 100 \mu \mathrm{m}$ of the center of the illuminated spot (see Fig. $2 A$ ). Photostimulation-evoked EPSCs were recorded from L2/3 pyramidal neurons. Usually, the photostimulations were applied once to each of $12 \times 30$ sites surrounding the recorded cells at intervals of $8 \mathrm{~s}$ in a quasi-random sequence. Control experiments measuring the spatial and temporal properties of action potentials evoked in cortical cells by photostimulation used extracellular loose-patch current-clamp recordings with patch pipettes filled with ACSF.

Analysis of EPSCs. The analysis of EPSCs evoked by photostimulation was conducted as described previously (Yoshimura et al., 2005). The maps of photostimulation sites were aligned to laminar borders in fixed and stained tissue (see Figs. $3 A, D, 4 A, D$ ), and each site was assigned a laminar identity. In slices obtained at 3 weeks, sites within $50 \mu \mathrm{m}$ of laminar borders were discarded from further analyses to limit the number of evoked synaptic currents arising from neurons with cell bodies potentially outside the stimulated layer. However, we did not adopt this procedure in slices obtained at P13-P15, because the thickness of layers was not sufficient. The electrical recordings obtained from photostimulation and no stimulation (control) trials were analyzed using peak analysis software from Synaptosoft and other custom software written in Matlab (RRID: nlx_153890). We measured the peak time and amplitude of all of the EPSCs occurring $<150 \mathrm{~ms}$ after the stimulation (see Figs. 3, 4). When an EPSC was preceded by EPSCs with short intervals, we extrapolated the decay of the preceding EPSCs using single exponential curves and subtracted the extrapolated curves from the EPSC,

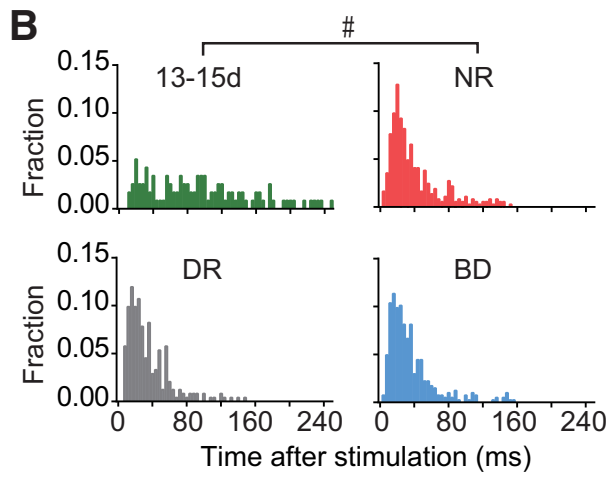

Figure 2. Effectiveness of photostimulation in evoking action potentials directly in cortical cells. $\boldsymbol{A}$, The numbers (mean \pm SEM) of action potentials evoked by photostimulation in L2 $-\mathrm{L} 5$ neurons were plotted against the distance from the center of laser spots the soma of recorded cells in rats at the age of P13-P15 (13-15d, green squares) and 3-week-old rats (22-28d) reared normally the loose-patch current-clamp recording method. The laser beam was shifted vertically through the center of the ennormal rats at P13-P15 (13-15d) and P22-P28 (22-28d) B Normalized poststimulus time histograms of spikes. The cells were sampled from rats at P13-P15 (top left, 13-15d), and 3-week-old rats reared normally (top right, NR), in darkness (bottom left, DR), and with binocular deprivation (bottom right, $B D$ ). The stimulation was repeated $\geq 3$ times. Kolmogorov-Smirnov test; $\# p<0.05$ between normal rats at P13-P15 and P22-P28. The number of cells was the same as in $\boldsymbol{A}$.

to determine its properties. The number of EPSCs evoked by photostimulation was determined by counting all of these temporally overlapped EPSCs as well as isolated EPSCs. The rise times of EPSCs were determined by the time taken for the amplitude to increase from 10 to $90 \%$ of its peak value. Cross-correlograms of EPSCs were computed for each pair of simultaneously recorded L2/3 pyramidal neurons; separate correlograms were computed for stimulation of each cortical layer (L2/3, L4, and L5). Cross-correlation data were binned into histograms using 4 $\mathrm{ms}$ bins, and the central bin included values of $0 \pm 2 \mathrm{~ms}$. Data from the stimulation trials (from the same layer) were also used to create shifted correlograms for each layer. We calculated a shifted correlogram for each layer after the EPSC data at each stimulation site was set to the next stimulation site on the right in one of the two simultaneously recorded cells. In the shifted correlogram, the number of EPSC events was divided by the ratio of the total number of EPSC combinations in the shifted correlogram to the total number in the nonshifted correlogram, to correct for the difference in the total number of EPSC combinations between the two correlograms. To test whether this procedure using a position shift for the calculation of shifted correlograms is adequate, we also constructed shifted correlograms from the data obtained from five pairs of cells sampled from normal rats at 3 weeks using another shuffling method. In these cases, the recording condition remained stable for a long period of time, and hence photostimulation could be applied twice at each site. We calculated a shifted correlogram after exchanging EPSC data at each site between the first and the second stimulation trials in one of the two simultaneously recorded cells. No statistically significant differences were found in the shifted correlograms constructed using these two shuffling methods for any of layers in any of the cell pairs (Kolmogorov-Smirnov test, $p>0.1$ ), demonstrating the validity of the procedure we used to construct shifted correlograms. To calculate the correlation probability in a pair of cells for each layer, the shifted correlogram was subtracted from the nonshifted correlogram for the same layer, and then the value in the central bin was divided by the estimated total number of evoked EPSCs (an average for the two cells) observed in all of the stimulation sites in the relevant layer. The number of evoked EPSCs was calculated as the total number of measured EPSCs for "cell $\mathrm{P}_{\mathrm{a}}$ " minus the number of spontaneous EPSCs, which were estimated from nostimulation trials for that cell, plus the same value calculated for "cell $\mathrm{P}_{\mathrm{b}}$," divided by two. No differences were found in the correlation probability values calculated using the two shuffling methods for any of layers in the five cell pairs (paired $t$ test, $p>0.1$ ). For analysis of asynchronous EPSCs, we examined EPSCs occurring in the temporal window from 100 to 400 

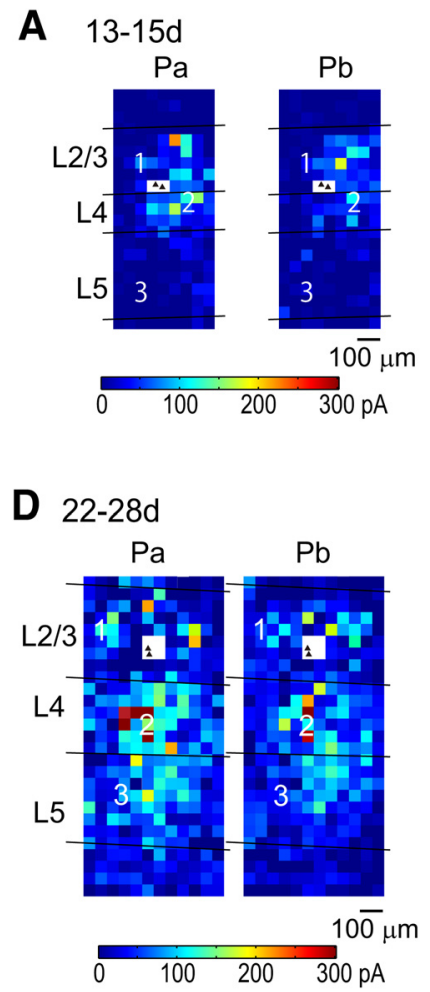
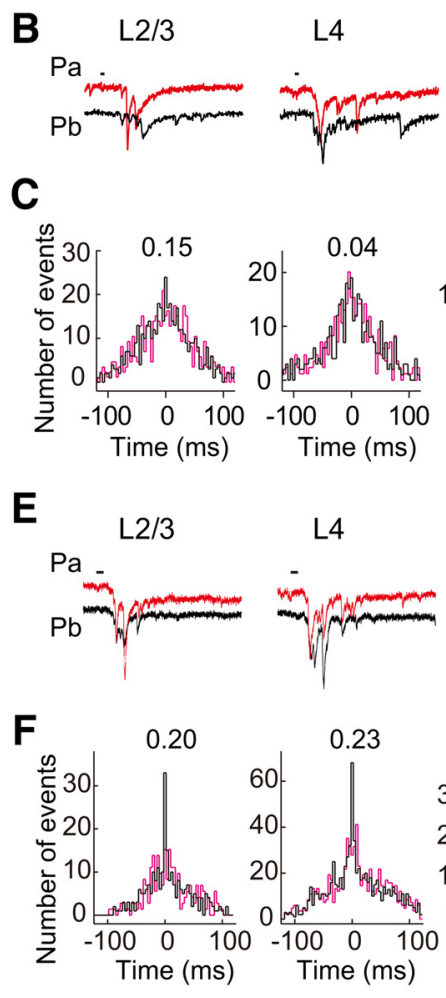

Figure 3. Cross-correlation analysis of photostimulation-evoked EPSCs in connected cell pairs in normal rats. $\boldsymbol{A}$, The color of each square indicates the sum of the amplitudes of EPSCs evoked in pyramidal cells $P_{a}$ and $P_{b}$ (filled triangles in a white square) by photostimulation at that site in a slice prepared from a rat just after eye opening (P13-P15). The laminar borders are shown, and the distance and color-coded scales are common. $\boldsymbol{B}$, EPSCs evoked in $\mathrm{P}_{\mathrm{a}}$ (red) and $\mathrm{P}_{\mathrm{b}}$ (black) by photostimulation at representative sites (squares numbered in $A$ ) in L2/3, L4, and L5. The short horizontal lines indicate the period of photostimulation. The time and current calibrations are common. C, Nonshifted (black) and shifted (magenta) cross-correlograms computed from EPSC data collected upon photostimulation in each layer. The figures attached to the plots indicate the correlation probability values in the cell pair. $\mathbf{D}-\boldsymbol{F}$, Similar to $\boldsymbol{A}-\boldsymbol{C}$, but results from a normally reared rat at P22-P28.

ms after photostimulation to avoid contamination of synchronous EPSCs.

Statistical analysis. Data are presented as mean \pm SEM. Statistical analyses were performed using Student's $t$ test, paired $t$ test, Mann-Whitney test, $\chi^{2}$ test or Kolmogorov-Smirnov test when two groups were compared, and one-way ANOVA test followed by Tukey's test or nonparametric Kruskal-Wallis test followed by Dunn's test when more than two groups were compared. $p$ values of $<0.05$ were considered significant.

\section{Results}

We used visual cortical slices obtained from three groups of 3-week-old (P22-P28) rats, which were reared in a normal visual environment (normal rats), or with binocular deprivation by lid suture from the day of eye opening (binocularly deprived rats), or in darkness from birth (dark-reared rats), as shown in Figure $1 A$. We also used rats at P13-P15, just after eye opening, to help clarify the role of experience on cortical development.

\section{The effect of visual experience on synaptic connections between adjacent $\mathrm{L} 2 / 3$ pyramidal cells}

We first analyzed the synaptic connections between adjacent $(<50 \mu \mathrm{m}) \mathrm{L} 2 / 3$ pyramidal cells using dual whole-cell recordings. Figure $1 B$ shows examples of action potentials evoked by brief depolarizing voltage pulses at intervals of $50 \mathrm{~ms}$ in one cell (upper traces) and resultant EPSCs in the other cell (lower traces) for each experimental group. The probability of excitatory connections between simultaneously recorded cells was low just after eye opening (10\%, 32 of 335 pairs), and markedly increased to $28 \%$
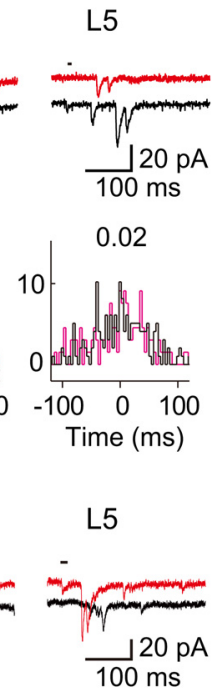

(27 of 98 pairs; $\chi^{2}$ test, $p<0.0001$ ) by 3 weeks in normal rats (Fig. $1 C$ ). Dark rearing prevented this developmental increase. In dark-reared rats, the connection probability (14\%, 16 of 113 pairs) was almost the same $(p>0.2)$ as that observed just after eye opening, and it was only half $(p<0.02)$ of that observed in agematched normal rats (Fig. $1 C$ ). In contrast to dark rearing, the connection probability in binocularly deprived rats $(30 \%, 21$ of 70 pairs) was not different $(p>0.7)$ from that in normal rats (Fig. 1C). Thus, dark rearing, but not binocular deprivation, disturbed developmental increases in synaptic connections between adjacent layer $2 / 3$ pyramidal cells.

In a small number of cell pairs, EPSCs were evoked in both directions. The probability of this reciprocal connection also increased during normal development (Fig. 1C). The probability of reciprocal connections was extremely low $(0.3 \%, 1$ of 335 pairs) just after eye opening, and increased $\sim 20$-fold during the following 2 weeks in a normal visual environment (6.1\%, 6 of 98 pairs; $p<0.0001)$. The probability of reciprocal connections in binocularly deprived rats $(4.3 \%, 3$ of 70 pairs) was slightly lower than that in normal rats and higher than that in darkreared rats $(1.7 \%, 2$ of 113 pairs), although the differences were statistically insignificant $(p>0.3)$. If the probability of connection in one direction is independent of the presence or absence of connection in the other direction, the probability to detect reciprocally connected pairs should be the square of the one-way connection probability. We found that the probability of reciprocally connected pairs was similar to the expected probability in each experimental group ( $p>0.2$; Fig. $1 C$ ). This suggests that the experience-dependent establishment of reciprocal connections proceeds similarly to that of one-way connections.

We characterized developmental changes in the properties of these unitary EPSCs recorded from pairs of adjacent layer 2/3 pyramidal cells (Fig. 1D-I). The amplitude of EPSCs showed developmental changes in parallel with the increase in connection probability (Fig. 1D). The amplitude increased $>2$-fold during this developmental period in rats with normal visual experience (Mann-Whitney test, $p<0.005$ ). The EPSC amplitude in dark-reared rats was significantly smaller (Dunn's test $p<0.05$ ) than that in normal rats and similar to that at P13-P15, whereas the amplitude in binocularly deprived rats was not different from that in normal rats $(p>0.05)$. During normal development, the failure rate of EPSCs (Mann-Whitney test, $p<0.01$ ) and the coefficient of variation (CV) of EPSC amplitude $(p<$ 0.05 ) became significantly smaller in the period from P13-P15 to 3 weeks (Fig. 1E,F) in association with the increase in EPSC amplitude, suggesting that the increase in EPSC amplitude is due to a presynaptic change in release probability and/or an increase in the number of functional synaptic sites, such as conversion from silent synapses to functional synapses or synaptogenesis. The paired-pulse ratio (PPR) of EPSCs, reflecting the efficacy of 
action potential-dependent transmitter release, did not show any significant change $(p>0.05$; Fig. $1 G)$. Thus, the number of functional synaptic sites in the unitary connection between pairs of $\mathrm{L} 2 / 3$ pyramidal cells may increase after eye opening in normal rats, leading to higher fidelity of synaptic transmission. Both the failure rate of EPSCs (Dunn's test, $p<$ $0.01)$ and the CV of EPSC amplitude $(p<$ 0.05 ) were significantly larger in darkreared than in normal rats, but the PPR was not different between them $(p>0.05$; Fig. $1 E-G)$, indicating that dark rearing keeps the synapses in an immature state. In contrast to dark-reared rats, all of the synaptic properties in binocularly deprived rats were indistinguishable from those in normal rats $(p>0.05$; Fig. $1 D-G)$.

No significant differences were found in the rise time of EPSCs during normal development from P13-P15 to 3 weeks (Mann-Whitney test, $p>0.4$ ), or between the 3-week-old groups (KruskalWallis test, $p>0.1$; Fig. $1 H$ ). The halfwidth of EPSCs was not different between the 3-week-old groups (Kruskal-Wallis test, $p>0.9$ ), although it increased significantly during normal development (MannWhitney test, $p<0.001$; Fig. $1 I)$. The input resistance of postsynaptic cells was not different between the 3-week-old groups (ANOVA, $p>0.4$ ), although it decreased significantly during normal development ( $t$ test, $p<0.0001$; Fig. $1 J$ ). There were no significant differences in series re-

sistance between the experimental groups (ANOVA, $p>0.05$; Fig. $1 K)$. These results indicate that the maturation of synaptic connections between L2/3 pyramidal cells is retarded by dark rearing, whereas in the presence of some level of visual inputs it proceeds normally, even without patterned vision.

\section{The effect of visual experience on excitatory inputs from L2- L5 neurons}

We then analyzed the monosynaptic EPSCs evoked in simultaneously recorded L2/3 pyramidal cells by the firing of other cortical neurons in L2-L5 resulting from focal glutamate uncaging with laser scanning photostimulation (Yoshimura et al., 2005). To compare the effectiveness of photostimulation in evoking action potentials directly in cortical neurons between the different experimental groups, we performed loose-patch current-clamp recordings from cortical cells. We uncaged MNI-glutamate by ultraviolet light for photostimulation of cortical cells for the three groups of rats at 3 weeks. We did not find any significant differences between these groups in the number of spikes elicited by photostimulation in L2-L5 cells (Kruskal-Wallis test, $p>0.5$; Fig. 2A). However, this photostimulation often made it difficult to keep the slices obtained at P13-P15 healthy. Thus, in these immature preparations, we used RuBi-glutamate for the photostimulation, as it can be effectively uncaged by visible light (Fino et al., 2009). We adjusted the intensity of photostimulation so that the effectiveness of photostimulation for slices at P13-P15

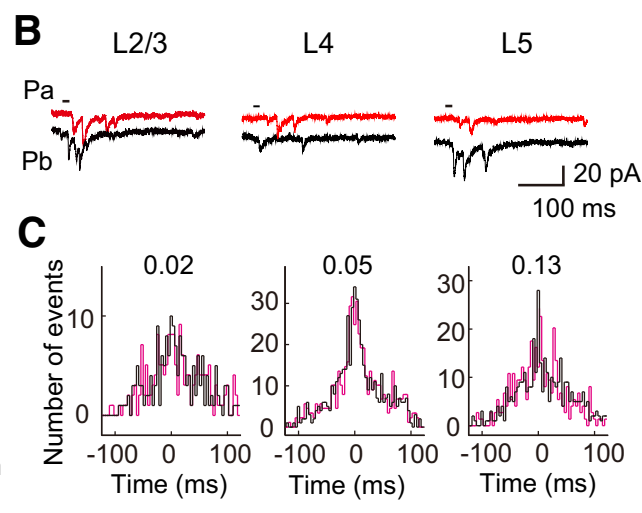

E

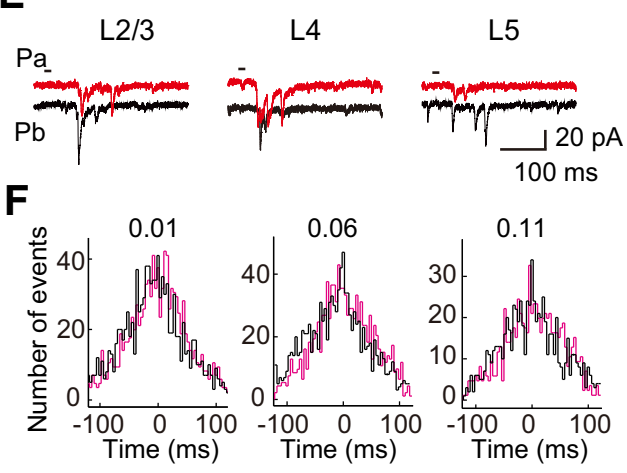


A

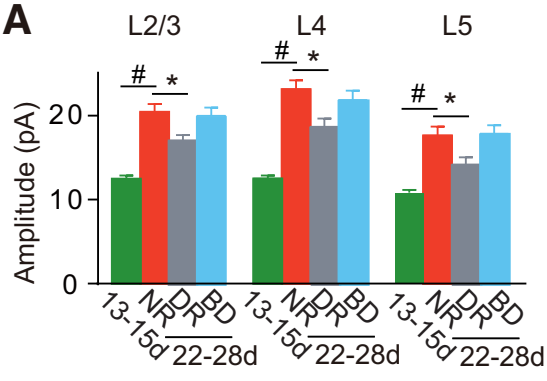

C

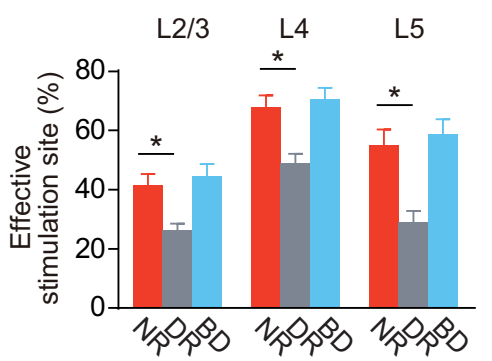

B

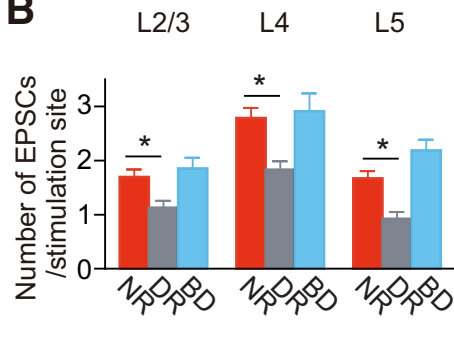

D

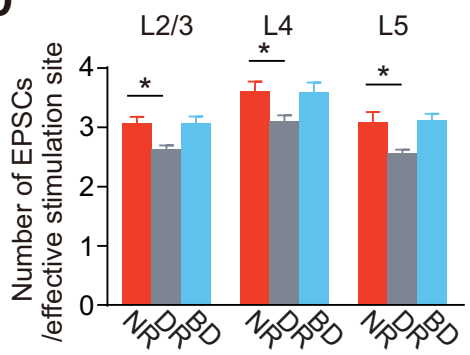

Figure 5. Comparison of photostimulation-evoked EPSCS. $A$, The amplitude of EPSCS (mean \pm SEM) evoked by photostimulation of each layer, expressed as an average for all stimulation sites in the relevant layer, in rats at P13-P15 (13-15d, $n=66$ cells) and 3-week-old rats (22-28d) reared normally (NR, $n=30$ ), in darkness (DR, $n=36$ ), and with binocular deprivation (BD, $n=$ 28). Mann-Whitney test; $\# p<0.05$ between normal rats at P13-P15 and P22-P28. Dunn's test; ${ }^{*} p<0.05$ versus normal rats (comparison between the 3-week-old groups). $\boldsymbol{B}$, The number of EPSCs (mean \pm SEM) evoked by photostimulation of each layer in 3-week-old rats reared normally (NR, $n=30$ cells), in darkness (DR, $n=36$ ), and with binocular deprivation ( $\mathrm{BD}, n=28)$. Dunn's test; ${ }^{*} p<0.05$ versus normal rats. $\boldsymbol{C}, \boldsymbol{D}$, Similar to $\boldsymbol{B}$, but the percentage of effective stimulation sites eliciting $\geq 2$ EPSCs $(\boldsymbol{C})$ and the number of EPSCS (mean \pm SEM) evoked by the stimulation of effective stimulation sites (D).

EPSCs. Thus, using these EPSCs, we estimated the amplitude of unitary EPSCs originating from the cells in each layer. The amplitude of EPSCs evoked by photostimulation of each cortical layer increased significantly after eye opening in normal rats (Mann-Whitney test, $p<0.05$; Fig. 5A). The amplitude of EPSCs was significantly smaller in dark-reared rats for each of stimulated cortical layers (Dunn's test, $p<0.05$ ), compared with normal rats, whereas binocular deprivation did not prevent the developmental increases at all $(p>0.05$; Fig. $5 A)$. Compared with EPSCs between simultaneously recorded L2/3 pyramidal cells (Fig. $1 D$ ), the amplitude of EPSCs evoked by photostimulation of L2/3 was significantly larger in rats at P13-P15 (MannWhitney test, $p<0.02$ ) and in 3-week-old rats reared in darkness $(p<0.0001)$, but not in 3-week-old rats reared normally $(p>$ 0.3 ) or with binocular deprivation ( $p>0.1$; Fig. $5 A)$. These differences observed in immature rats and dark-reared rats may be ascribed to the higher failure rate of synaptic transmission in these rats (Fig. $1 E$ ), because the amplitude of EPSCs was averaged for all of the stimulation trials, including those that resulted in transmission failure in the study of EPSCs between cell pairs. Indeed, the amplitude of EPSCs evoked by photostimulation of L2/3 (Fig. 5A) was not different $(p>0.09)$ from the amplitude of EPSCs averaged for only successful transmission between cell pairs in any of the experimental groups (P13-P15: $12.7 \pm 1.8 \mathrm{pA}$, $n=32$ pairs; normal 3 weeks: $19.6 \pm 1.9 \mathrm{pA}, n=27$; dark rearing: $14.5 \pm 1.5 \mathrm{pA}, n=16$; binocular deprivation: $21.1 \pm 3.1 \mathrm{pA}, n=$ 21). The results for the EPSCs evoked by photostimulation of L4 and L5 were similar to those for the EPSCs evoked by photostimulation of L2/3 (Fig. 5A). This suggests that the number of functional synaptic sites in the unitary connection to a single L2/3 pyramidal cell from individual cortical cells commonly increases during normal development, leading to an increase in the unitary EPSC amplitude. This also suggests that this developmental change is disturbed by dark rearing but not binocular deprivation.

To further characterize developmental changes in synaptic connections to the recorded cells, we also counted the number of EPSCs evoked by the stimulation of each layer. The effectiveness of photostimulation to elicit action potentials in cortical cells was not identical between the two different age groups (Fig. 2A). In addition, the density of cortical neurons decreases considerably during the 2 weeks after eye opening. As a result, the number of neurons activated by photostimulation of each site would decrease during this period. Therefore, we only compared the number of EPSCs between the 3-week-old groups, although the number at P13-P15 was in a range $(\mathrm{L} 2 / 3,2.6 \pm 0.2 ; \mathrm{L} 4,2.5 \pm$ $0.2 ; \mathrm{L} 5,1.5 \pm 0.1 ; n=66 \mathrm{~L} 2 / 3$ pyramidal cells) that was not so different from the range observed at 3 weeks (Fig. 5B). The number of EPSCs evoked by photostimulation of each layer, expressed as an average for all stimulation sites in the relevant layer, was significantly lower in darkreared rats, compared with normal rats (Dunn's test, $p<0.05$ ), although there were no differences in the number of EPSCs between binocularly deprived and normal rats for any of stimulated layers ( $p>0.05$; Fig. $5 B)$. The number of EPSCs averaged for all of the stimulation sites in L2-L5 was $2.0 \pm 0.1(n=$ 30 cells) in normal rats. We defined effective stimulation sites as those sites at which the number of EPSCs evoked by photostimulation was $\geq 2$. The proportion of effective stimulation sites was smaller in dark-reared rats than in normal rats for any of layers (Dunn's test, $p<0.05$ ), whereas it was not different between binocularly deprived and normal rats $(p>0.05$; Fig. $5 C)$. The number of EPSCs evoked by photostimulation of effective stimulation sites in each layer was significantly lower in darkreared rats, compared with normal rats (Dunn's test, $p<$ 0.05 ), although there were no differences in that number between binocularly deprived and normal rats for any of stimulated layers $(p>0.05$; Fig. $5 D)$. These results indicate that dark rearing reduced both the proportion of effective stimulation sites and the effectiveness at effective stimulation sites in any of stimulated layers, whereas binocular deprivation affected neither of them.

Because the effectiveness of photostimulation in eliciting action potentials in cortical cells did not differ between the 3-weekold groups (Fig. 2A) and dark rearing does not affect the density of the visual cortical neurons in rats (Gabbott et al., 1986), the difference in the number of EPSCs between these groups may be ascribed to the difference in the number of cells sending functional inputs to the recorded cells and/or the frequency of transmission failure in the functional unitary inputs. The frequency of transmission failure depends on the probability of action potential-dependent transmitter release. In addition, the frequency also depends on the number of functional synaptic sites in the unitary input originating from single presynaptic cells, be- 
cause transmission failure in the connection is expected to decrease with an increase in the number of the functional sites. The analysis of the PPR of EPSCs failed to detect any differences in the release probability in synaptic connections between L2/3 pyramidal cells between the 3-week-old groups (Fig. 1G). Therefore, it is likely that the number of EPSCs can be influenced by the number of cells sending functional inputs and/or the number of functional synaptic sites in the unitary connection originating from single presynaptic cells, but not by the transmitter release probability. The analyses of synaptic connections between simultaneously recorded L2/3 pyramidal cells demonstrated that the connection probability was lower and the frequency of transmission failure was higher in darkreared rats, compared with normal rats, whereas there were no differences in these parameters between normal and binocularly deprived rats (Fig. 1C,E). These observations predict that the number of EPSCs evoked by photostimulation of $\mathrm{L} 2 / 3$ in normal rats will be larger than that in dark-reared rats, but not different from that in binocularly deprived rats. We obtained results consistent with this prediction for the stimulation of $\mathrm{L} 2 / 3$, and almost the same results for the stimulation of L4 and L5 (Fig. 5B). Considering the analyses of EPSCs using the two methods together, it is likely that the number of cells sending functional inputs to $\mathrm{L} 2 / 3$ pyramidal cells from L4 and L5 as well as $\mathrm{L} 2 / 3$ and the number of functional synaptic sites in these unitary connections both increase during normal development, and this developmental change is disturbed by dark rearing but not binocular deprivation.

\section{The effect of visual experience on quantal EPSCs originating from L2-L5 cells}

To further characterize developmental changes in synaptic transmission, we analyzed quantal EPSCs occurring asynchronously following synchronous EPSCs in a modified ACSF containing $\mathrm{Sr}^{2+}$ instead of $\mathrm{Ca}^{2+}$, as shown in Figure $6 A$ (Goda and Stevens, 1994; Oliet et al., 1996). We estimated the quantal amplitude of EPSCs evoked in L2/3 pyramidal cells by photostimulation of cells in each layer. No significant differences were found in quantal amplitude between any of the groups for any of layers stimulated (Fig. $6 B$ ), indicating that the amplitude of quantal EPSCs originating from L2-L5 cells to L2/3 pyramidal cells remains unchanged during the 2 weeks after eye opening, regardless of visual experience. During normal development, the rise time of quantal EPSCs in inputs originating from L2/3 cells increased significantly (Mann-Whitney test, $p<0.008)$, whereas those in inputs originating from other layers did not show any significant changes $(p>0.4$; Fig. $6 C)$. Visual deprivation did not affect these developmental 3-week-old groups.
B

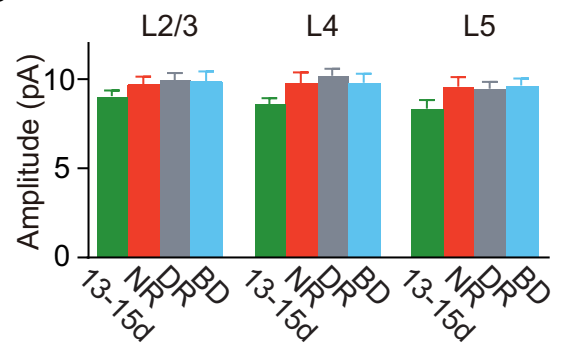

C

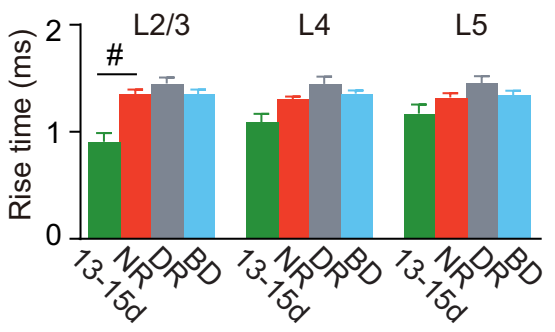

D

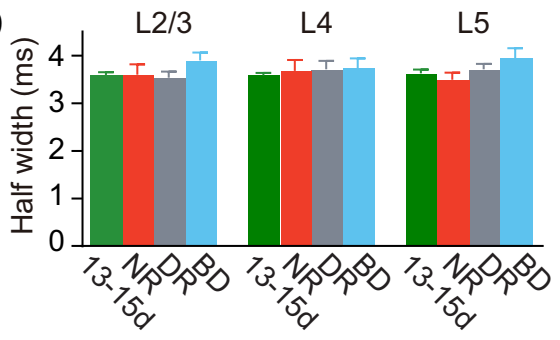

Figure 6. Comparison of photostimulation-evoked quantal EPSCS. A, Representative asynchronous EPSC recorded from a rat at 1515-15d) and 3-week-old rats (22-28d) reared normally (NR), in darkness (DR), and with binocular deprivation (BD). The 8 cells; NR, $n=5$ cells; DR, $n=9$ cells; BS, $n=5$ cells). Mann-Whitney test; $\# p<0.05$ between normal rats at P13-P15 and P22-P28. No significant differences (Kruskal-Wallis test, $p>0.26$ ) were found in any of parameters shown in $\boldsymbol{B}-\boldsymbol{F}$ between the

changes (Kruskal-Wallis test, $p>0.2$; Fig. $6 C$ ). No significant differences were found in the half-width of quantal EPSCs between any of the groups for any of stimulated layers ( $p>0.05$; Fig. $6 D)$. The input resistance of recorded cells at P13-P15 was significantly higher than that at 3 weeks ( $t$ test, $p<0.05$ ), while no significant differences were found between the 3-week-old groups (ANOVA, $p>0.3$; Fig. $6 E$ ). There were no significant differences in series resistance between the experimental groups (ANOVA, $p>0.1$; Fig. $6 F$ ). Therefore, the amplitude and time course of quantal EPSCs remained unchanged during this developmental period, except for the increase in the rise time of EPSCs originating from L2/3 cells. Visual experience did not affect the development of these properties. This visual experience-independent development of quantal EPSCs is consistent with the results of our experiments conducted in mice using $\mathrm{Sr}^{2+}$ (Funahashi et al., 2013), but not with the results of experiments in which miniature EPSCs were examined in the presence of tetrodotoxin (TTX; Desai et al., 2002; Goel and Lee, 2007). Although it is uncertain what caused this difference, one possible explanation is the differences in the methods used in these studies, such as usage of TTX or $\mathrm{Sr}^{2+}$, and EPSC recordings in the presence of $\mathrm{GABA}_{\mathrm{A}}$ receptor an- 
A $L 2 / 3$ stim

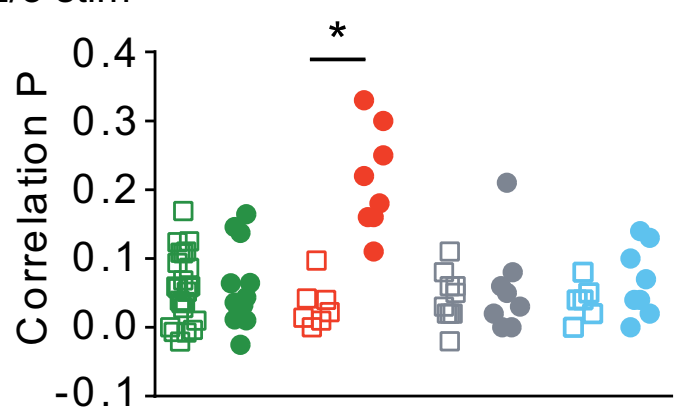

B

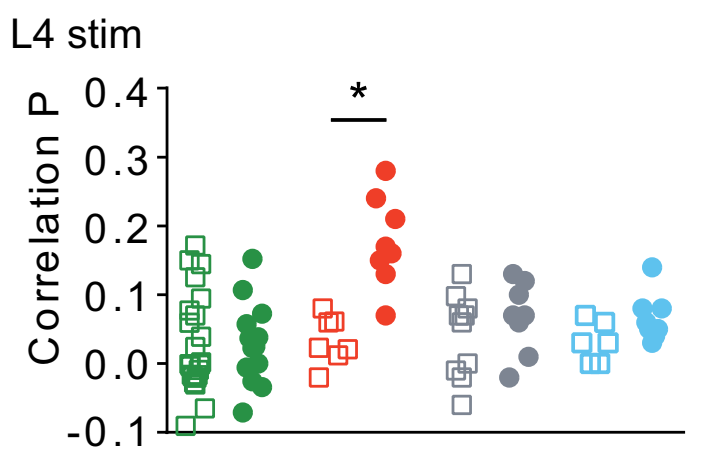

C

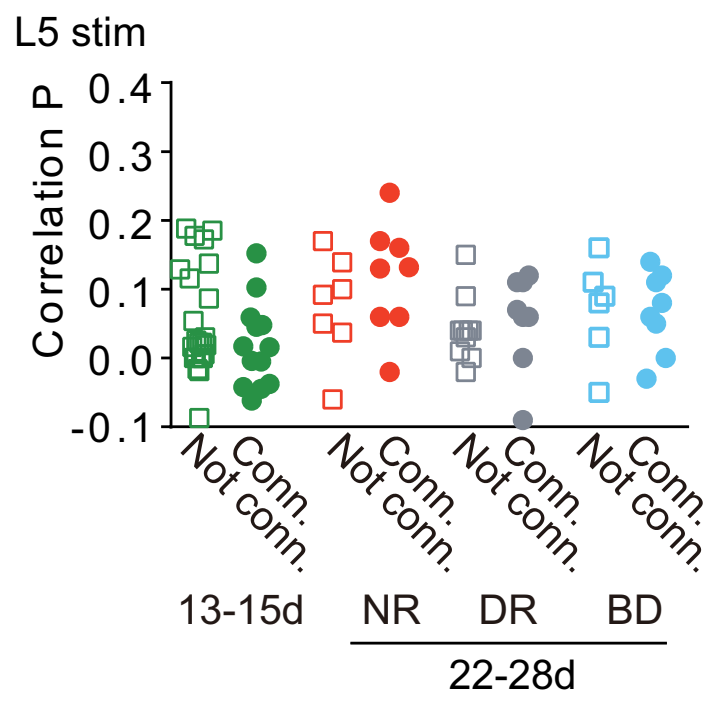

Figure 7. Comparison of correlation probability of photostimulation-evoked EPSCs. A-C, Correlation probabilities for EPSCs evoked by stimulation of L2/3 (A), L4 (B), and L5 (C) in unconnected (squares) and connected (circles) cell pairs in rats at P13-P15 (13-15d, $n=33$ cell pairs) and 3-week-old rats (22-28d) reared normally (NR, $n=15)$, in darkness (DR, $n=18$ ), and with binocular deprivation (BD, $n=14) . t$ test; ${ }^{*} p<0.05$ between unconnected and connected pairs in each group.

tagonists or at the reversal potential of inhibitory synaptic transmission in the absence of these antagonists.

\section{The effect of visual experience on the establishment of fine-scale networks}

We previously reported that, in normal visual cortical slices, adjacent L2/3 pyramidal cell pairs frequently shared common inputs from nearby excitatory cells in L2/3 and L4, only when they were monosynaptically connected, demonstrating the presence of fine-scale networks (Yoshimura et al., 2005). To test whether visual experience is required for the establishment of the fine- scale networks, we estimated the number of shared EPSCs from the difference between two cross-correlograms calculated from nonshifted and shifted photostimulation trials (Figs. 3C,F, 4C,F, black, magenta lines), and calculated the correlation probability for EPSCs, a ratio of the number of shared to total EPSCs, which reflects the proportion of common inputs. In normal rats at the age of 3 weeks, the correlation probability was significantly higher for connected $(n=7)$ than unconnected cell pairs $(n=8)$ for stimulation sites in L2/3 and L4 ( $t$ test, $p<0.001$; Fig. $7 A, B$ ), while a low correlation probability was found for both connected and unconnected cell pairs for stimulation sites in L5 ( $p>0.33$; Fig. $7 C$ ). These results were consistent with those of our previous study (Yoshimura et al., 2005).

In contrast, no significant differences were found in the correlation probability between connected $(n=13)$ and unconnected cell pairs $(n=20)$ for any of the stimulated layers at P13-P15 ( $p>0.2$; Fig. 7 ), and the values of correlation probability were similar to those shown for unconnected cell pairs in normal rats (ANOVA, $p>0.22$; Fig. 7). Thus, in immature cortex just after eye opening, L2/3 pyramidal cell pairs rarely shared excitatory inputs from any of the stimulated layers, even when they were connected monosynaptically, indicating the absence of fine-scale networks. Furthermore, in rats subjected to dark rearing or binocular deprivation, no significant differences were found in the correlation probability between connected and unconnected cell pairs for any of the stimulated layers at 3 weeks $(p>0.14)$, at which time the fine-scale networks were already established in normal rats, and the values of correlation probability were almost the same as those shown for unconnected cell pairs in normal rats (ANOVA, $p>0.14$; Fig. 7). Thus, L2/3 pyramidal cell pairs rarely shared excitatory inputs from any layers, regardless of the presence or absence of monosynaptic connections in the cell pairs, indicating the absence of fine-scale networks in either type of deprived animals. The failure of these networks to emerge in binocularly deprived animals may be ascribed to a reduced intensity of retinal illumination and/or the absence of patterned visual input. It is known that the eyelids attenuate incident light by $\sim 2$ log units in young cats (Loop and Sherman, 1977; Spear et al., 1978). A considerable proportion of visual cortical cells respond to diffuse dark/light stimulation presented through the sutured eyelids (Spear et al., 1978) and animals maintain a good capability to discriminate light/dark differences but not stripe orientation while their eyelids are sutured (Loop and Sherman, 1977). The effects of photic deprivation at the retina may be considerably offset by increased pupillary dilatation and retinal sensitivity during binocular deprivation. In addition, after the contrast of one retinal image was abolished with no difference in the mean intensity of retinal illumination between two eyes during postnatal development, the responsiveness of visual cortical neurons to the stimulation of that eye was totally lost, whereas after retinal illumination was reduced by a $2 \log$ unit neutral density filter in one eye with contrast reserved, the visual responsiveness to the stimulation of that eye was not affected (Blakemore, 1976), indicating that visual cortical circuitry is affected by the spatial pattern of retinal illumination far more than by its mean intensity. Thus, we believe that patterned vision after eye opening is most likely required for the establishment of fine-scale networks.

\section{Discussion}

We studied the development of excitatory synaptic connections to L2/3 pyramidal neurons from adjacent cortical neurons in rat visual cortical slices. The connection probability between L2/3 
pyramidal neurons and the strength of synaptic connections to L2/3 pyramidal cells from L2-L 5 cells both increased during the 2 weeks after eye opening in normal rats. This developmental change was prevented by dark rearing but not binocular deprivation, indicating that diffuse light stimulation is sufficient for the maturation of individual synaptic connections (Fig. 8). The fine-scale networks were absent just after eye opening and established during the subsequent 2 weeks in normal rats. Dark rearing and binocular deprivation both abolished the establishment of those networks totally, indicating that the fine-scale networks emerge only in the presence of patterned vision (Fig. 8).

\section{The effects of early visual experience on the maturation of individual synaptic connections}

The present study demonstrated that the establishment and maturation of synaptic connections were regulated by visual experience. The probability of synaptic connections between simultaneously recorded $\mathrm{L} 2 / 3$ pyramidal cells was very low just after eye opening and increased steeply during the following 2 weeks. This developmental change was prevented by dark rearing. In addition, fewer EPSCs were evoked in L2/3 pyramidal cells by photostimulation of L4 and L5 cells as well as L2/3 cells in dark-reared rats, compared with normally reared rats, suggesting that the number of cells sending excitatory inputs to L2/3 pyramidal cells increases in all of these layers during the 2 weeks after eye opening, depending on visual experience. This time period coincides with the time when stimulation of presynaptic neurons paired with postsynaptic depolarization frequently induces NMDA receptor-dependent long-term potentiation (LTP) in L2/3 pyramidal cells (Yoshimura et al., 2003; Jiang et al., 2007) and silent synapses with NMDA receptors, but not AMPA receptors, are frequently converted to functional synapses with both types of receptors in connections to L2/3 pyramidal cells in rodent visual cortex (Rumpel et al., 2004; Funahashi et al., 2013). This kind of conversion was observed in various synaptic connections during early development (Isaac et al., 1995; Liao et al., 1995; Durand et al., 1996; Wu et al., 1996). Thus, the establishment of functional synaptic connections to L2/3 pyramidal cells may be induced by visual inputs via the NMDA receptor-dependent LTP mechanism.

This view is consistent with the developmental changes in the properties of synaptic transmission. In normal development, unitary EPSCs between adjacent L2/3 pyramidal cells were significantly smaller in amplitude, higher in failure rate, and larger in CV of their amplitude just after eye opening, compared with 1-2 weeks after eye opening, although there was no difference in the quantal amplitude of EPSCs or the probability of action potential-dependent transmitter release between the two developmental stages. Dark rearing prevented these developmental changes and kept the synapses in an immature state. These observations suggest that the number of functional synapses mediating unitary EPSCs is increased by visual experience after eye opening, leading to the maturation of synaptic connections.

\section{Normal visual inputs}

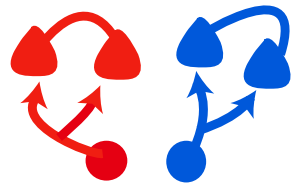

No visual inputs

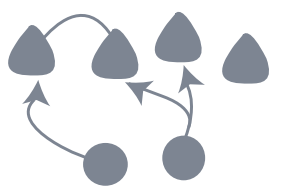

No patterned visual inputs

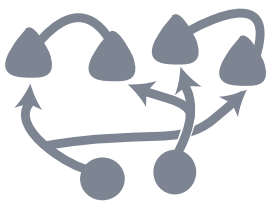

Figure 8. Schematic illustration of development of fine-scale networks and individual synaptic connections. The development of excitatory synaptic connections from L4 cells to L2/3 pyramidal cells during the period from eye opening (left) to 2 weeks after

In contrast to dark rearing, binocular deprivation did not affect normal developmental changes in connection probability or the properties of EPSCs. One may suppose that the probability and strength of connections to L2/3 pyramidal cells after binocular deprivation would be both less than those after normal vision, which was different from our experimental results, because visual responses of cortical cells during binocular deprivation are expected to be weaker than those during normal vision. However, visual stimulation through the sutured eyelids produces activity of cortical cells, which is sufficient to terminate the critical period of visual response modification, although dark rearing prevents the termination of that period (Cynader and Mitchell, 1980; Mower et al., 1981). Therefore, diffuse light stimulation may produce neural activities, which are sufficient for the maturation of synapses.

\section{The effects of early visual experience on local cortical connectivity}

The fine-scale networks were absent just after eye opening and established during the following 2 weeks. Dark rearing and binocular deprivation both prevented the emergence of these networks entirely. Thus, the fine-scale networks require patterned visual inputs for their establishment, which is different from the maturation of individual synapses. These findings clearly showed for the first time that early normal visual experience creates local cell assemblies composed of neurons specifically interconnected in visual cortex.

Although there were no differences in the probability and strength of synaptic connections to L2/3 pyramidal cells between normal and binocularly deprived cortices, their network organizations were quite different. This may be explained if we assume that the initial connections from L2/3 and L4 excitatory cells to L2/3 pyramidal cells include many silent synapses in addition to functional synapses, and that the silent synapses are formed independent of the similarity of visual responsiveness. During nor- 
mal development, simultaneous firing may occur frequently in pairs of cells with similar visual responsiveness but rarely in pairs of cells with different visual responsiveness after eye opening, because response selectivity in cortical cells is already established at the time of eye opening. After the conversion of silent to functional synapses and the conversion of functional to silent synapses based on the Hebbian synaptic modification rule (Bear et al., 1987; Singer, 1995; Katz and Shatz, 1996; Zhang and Poo, 2001; Xiao et al., 2004), cell pairs with similar responsiveness may preferentially acquire functional connections, and cell pairs with different visual responsiveness may lose functional connections and/or fail to acquire functional connections. This possibility was supported by a recent study in which synaptic connections were examined in visual cortical slices prepared from normal mice after visual responsiveness of cortical cells was determined in vivo using the two-photon $\mathrm{Ca}^{2+}$ imaging method (Ko et al., 2011, 2013). These studies demonstrated that $\mathrm{L} 2 / 3$ pyramidal neurons with similar visual responsiveness were preferentially connected at 2 weeks after eye opening, whereas such specific connections were observed far less at the time of eye opening. In addition, L2/3 pyramidal cell pairs that are connected may often acquire common inputs from the cells with visual responsiveness similar to that of the cell pairs, because these cells all have similar visual responsiveness and hence synchronized firing takes place frequently in these cells, leading to the establishment of the finescale networks.

During binocular deprivation, weakly synchronized firing may occur in cortical cells, independent of the similarity of their visual responsiveness, because visual cortical cells may respond to the onset and/or offset of diffuse light through the sutured eyelids, but not to patterned visual inputs. Thus, it is unlikely that cells with similar visual responsiveness are selectively connected, although activity-dependent establishment and strengthening of synaptic connections can proceed. This may lead to a failure in the establishment of fine-scale networks.

\section{Functional roles of fine-scale networks}

Recent studies conducted in mice using the two-photon $\mathrm{Ca}^{2+}$ imaging method demonstrated that a considerable level of orientation selectivity was observed soon after eye opening, and the improvement of orientation selectivity proceeded without visual experience (Rochefort et al., 2011; Ko et al., 2013). In addition, sister neurons generated from the same progenitor cell show similar orientation preferences, suggesting that the establishment of orientation selectivity may depend considerably on genetic mechanisms (Li et al., 2012; Ohtsuki et al., 2012). Considered together, these findings suggest that visual response selectivity may be considerably established before visual experience, and that visual experience may not be so critical for improving the selectivity of visual responsiveness in rodent visual cortex, compared with higher mammals with well developed vision (Frégnac and Imbert, 1984; Chapman and Stryker, 1993; Li et al., 2006; Rochefort et al., 2011; Ko et al., 2013). Therefore, it is unlikely that fine-scale networks are fundamental to visual response selectivity. Neurons belonging to the same fine-scale network seem to share common visual responsiveness, because connected L2/3 pyramidal cells preferentially respond to similar visual features (Ko et al., 2011). Therefore, these fine-scale networks may contribute to the enhancement of optimal visual responses and increase the robustness of selective visual responsiveness. Another possible role could be to synchronize the firing of cells belonging to a cell assembly with similar visual responsiveness. The crosscorrelation analysis of spike trains in simultaneously recorded cells demonstrated that pairs of cells showing synchronized firing had similar visual responsiveness in cat visual cortex (Toyama et al., 1981; Ts'o et al., 1986; Eckhorn et al., 1988; Gray and Singer, 1989; Hata et al., 1991), suggesting that these cells receive common inputs from adjacent cortical cells that have visual responsiveness similar to their own. Synchronized firing of multiple neurons seems to play important roles in the temporal coding of visual objects (Singer, 1993; Usrey and Reid, 1999; Freiwald et al., 2001; Salinas and Sejnowski, 2001). Although the functional roles of the fine-scale networks are uncertain at present, these networks may be involved in some aspects of visual functions, such as visual acuity and binocular matching of orientation preference, that develop in parallel with the networks (Prusky et al., 2000, 2004; Kang et al., 2013).

\section{References}

Bear MF, Cooper LN, Ebner FF (1987) A physiological basis for a theory of synapse modification. Science 237:42-48. CrossRef Medline

Blakemore C (1976) The conditions required for the maintenance of binocularity in the kitten visual cortex. J Physiol 261:423-444. Medline

Chapman B, Stryker MP (1993) Development of orientation selectivity in ferret visual cortex and effects of deprivation. J Neurosci 13:5251-5262. Medline

Chapman B, Stryker MP, Bonhoeffer T (1996) Development of orientation preference maps in ferret primary visual cortex. J Neurosci 16:6443-6453. Medline

Crair MC, Gillespie DC, Stryker MP (1998) The role of visual experience in the development of columns in cat visual cortex. Science 279:566-570. CrossRef Medline

Crawford ML, Marc RE (1976) Light transmission of cat and monkey eyelids. Vision Res 16:323-324. CrossRef Medline

Cynader M, Mitchell DE (1980) Prolonged sensitivity to monocular deprivation in dark-reared cats. J Neurophysiol 43:1026-1040. Medline

Desai NS, Cudmore RH, Nelson SB, Turrigiano GG (2002) Critical periods for experience-dependent synaptic scaling in visual cortex. Nat Neurosci 5:783-789. Medline

Durand GM, Kovalchuk Y, Konnerth A (1996) Long-term potentiation and functional synapse induction in developing hippocampus. Nature 381: 71-75. CrossRef Medline

Eckhorn R, Bauer R, Jordan W, Brosch M, Kruse W, Munk M, Reitboeck HJ (1988) Coherent oscillations: a mechanism of feature linking in the visual cortex? Multiple electrode and correlation analyses in the cat. Biol Cybern 60:121-130. CrossRef Medline

Fino E, Araya R, Peterka DS, Salierno M, Etchenique R, Yuste R (2009) RuBi-glutamate: two-photon and visible-light photoactivation of neurons and dendritic spines. Front Neural Circuits 3:2. CrossRef Medline

Frégnac Y, Imbert M (1984) Development of neuronal selectivity in primary visual cortex of cat. Physiol Rev 64:325-434. Medline

Freiwald WA, Kreiter AK, Singer W (2001) Synchronization and assembly formation in the visual cortex. Prog Brain Res 130:111-140. CrossRef Medline

Funahashi R, Maruyama T, Yoshimura Y, Komatsu Y (2013) Silent synapses persist into adulthood in layer $2 / 3$ pyramidal neurons of visual cortex in dark-reared mice. J Neurophysiol 109:2064-2076. CrossRef Medline

Gabbott PL, Stewart MG, Rose SP (1986) The quantitative effects of darkrearing and light exposure on the laminar composition and depth distribution of neurons and glia in the visual cortex (area 17) of the rat. Exp Brain Res 64:225-232. CrossRef Medline

Goda Y, Stevens CF (1994) Two components of transmitter release at a central synapse. Proc Natl Acad Sci U S A 91:12942-12946. CrossRef Medline

Gödecke I, Bonhoeffer T (1996) Development of identical orientation maps for two eyes without common visual experience. Nature 379:251-254. CrossRef Medline

Goel A, Lee HK (2007) Persistence of experience-induced homeostatic synaptic plasticity through adulthood in superficial layers of mouse visual cortex. J Neurosci 27:6692-6700. CrossRef Medline

Gray CM, Singer W (1989) Stimulus-specific neuronal oscillations in orientation columns of cat visual cortex. Proc Natl Acad Sci U S A 86:16981702. CrossRef Medline 
Hata Y, Tsumoto T, Sato H, Tamura H (1991) Horizontal interactions between visual cortical neurones studied by cross-correlation analysis in the cat. J Physiol 441:593-614. Medline

Hubel DH (1982) Exploration of the primary visual cortex, 1955-78. Nature 299:515-524. CrossRef Medline

Huberman AD, Feller MB, Chapman B (2008) Mechanisms underlying development of visual maps and receptive fields. Annu Rev Neurosci 31: 479-509. CrossRef Medline

Isaac JT, Nicoll RA, Malenka RC (1995) Evidence for silent synapses: implications for the expression of LTP. Neuron 15:427-434. CrossRef Medline

Jiang B, Treviño M, Kirkwood A (2007) Sequential development of longterm potentiation and depression in different layers of the mouse visual cortex. J Neurosci 27:9648-9652. CrossRef Medline

Kang E, Durand S, LeBlanc JJ, Hensch TK, Chen C, Fagiolini M (2013) Visual acuity development and plasticity in the absence of sensory experience. J Neurosci 33:17789-17796. CrossRef Medline

Katz LC, Shatz CJ (1996) Synaptic activity and the construction of cortical circuits. Science 274:1133-1138. CrossRef Medline

Ko H, Hofer SB, Pichler B, Buchanan KA, Sjöström PJ, Mrsic-Flogel TD (2011) Functional specificity of local synaptic connections in neocortical networks. Nature 473:87-91. CrossRef Medline

Ko H, Cossell L, Baragli C, Antolik J, Clopath C, Hofer SB, Mrsic-Flogel TD (2013) The emergence of functional microcircuits in visual cortex. Nature 496:96-100. CrossRef Medline

Liao D, Hessler NA, Malinow R (1995) Activation of postsynaptically silent synapses during pairing-induced LTP in CA1 region of hippocampal slice. Nature 375:400-404. CrossRef Medline

Li Y, Fitzpatrick D, White LE (2006) The development of direction selectivity in ferret visual cortex requires early visual experience. Nat Neurosci 9:676-681. CrossRef Medline

Li Y, Lu H, Cheng PL, Ge S, Xu H, Shi SH, Dan Y (2012) Clonally related visual cortical neurons show similar stimulus feature selectivity. Nature 486:118-121. Medline

Loop MS, Sherman SM (1977) Visual discriminations during eyelid closure in the cat. Brain Res 128:329-339. Medline

Mower GD, Berry D, Burchfiel JL, Duffy FH (1981) Comparison of the effects of dark rearing and binocular suture on development and plasticity of cat visual cortex. Brain Res 220:255-267. Medline

Ohtsuki G, Nishiyama M, Yoshida T, Murakami T, Histed M, Lois C, Ohki K (2012) Similarity of visual selectivity among clonally related neurons in visual cortex. Neuron 75:65-72. CrossRef Medline

Oliet SH, Malenka RC, Nicoll RA (1996) Bidirectional control of quantal size by synaptic activity in the hippocampus. Science 271:1294-1297. CrossRef Medline

Perin R, Berger TK, Markram H (2011) A synaptic organizing principle for cortical neuronal groups. Proc Natl Acad Sci U S A 108:5419-5424. CrossRef Medline

Prusky GT, West PW, Douglas RM (2000) Experience-dependent plasticity of visual acuity in rats. Eur J Neurosci 12:3781-3786. CrossRef Medline

Prusky GT, Alam NM, Beekman S, Douglas RM (2004) Rapid quantifica- tion of adult and developing mouse spatial vision using a virtual optomotor system. Invest Ophthalmol Vis Sci 45:4611-4616. CrossRef Medline

Rochefort NL, Narushima M, Grienberger C, Marandi N, Hill DN, Konnerth A (2011) Development of direction selectivity in mouse cortical neurons. Neuron 71:425-432. CrossRef Medline

Rumpel S, Kattenstroth G, Gottmann K (2004) Silent synapses in the immature visual cortex: layer-specific developmental regulation. J Neurophysiol 91:1097-1101. Medline

Salinas E, Sejnowski TJ (2001) Correlated neuronal activity and the flow of neural information. Nat Rev Neurosci 2:539-550. CrossRef Medline

Singer W (1993) Synchronization of cortical activity and its putative role in information processing and learning. Annu Rev Physiol 55:349-374. Medline

Singer W (1995) Development and plasticity of cortical processing architectures. Science 270:758-764. CrossRef Medline

Song S, Sjöström PJ, Reigl M, Nelson S, Chklovskii DB (2005) Highly nonrandom features of synaptic connectivity in local cortical circuits. PLoS Biol 3:e68. CrossRef Medline

Spear PD, Tong L, Langsetmo A (1978) Striate cortex neurons of binocularly deprived kittens respond to visual stimuli through the closed eyelids. Brain Res 155:141-146. Medline

Toyama K, Kimura M, Tanaka K (1981) Cross-correlation analysis of interneuronal connectivity in cat visual cortex. J Neurophysiol 46:191-201. Medline

Ts'o DY, Gilbert CD, Wiesel TN (1986) Relationships between horizontal interactions and functional architecture in cat striate cortex as revealed by cross-correlation analysis. J Neurosci 6:1160-1170. Medline

Usrey WM, Reid RC (1999) Synchronous activity in the visual system. Annu Rev Physiol 61:435-456. CrossRef Medline

Wang BS, Sarnaik R, Cang J (2010) Critical period plasticity matches binocular orientation preference in the visual cortex. Neuron 65:246-256. CrossRef Medline

White LE, Coppola DM, Fitzpatrick D (2001) The contribution of sensory experience to the maturation of orientation selectivity in ferret visual cortex. Nature 411:1049-1052. CrossRef Medline

Wiesel TN (1982) The postnatal development of the visual cortex and the influence of environment. Biosci Rep 2:351-377. CrossRef Medline

Wu G, Malinow R, Cline HT (1996) Maturation of a central glutamatergic synapse. Science 274:972-976. CrossRef Medline

Xiao MY, Wasling P, Hanse E, Gustafsson B (2004) Creation of AMPAsilent synapses in the neonatal hippocampus. Nat Neurosci 7:236-243. CrossRef Medline

Yoshimura Y, Ohmura T, Komatsu Y (2003) Two forms of synaptic plasticity with distinct dependence on age, experience, and NMDA receptor subtype in rat visual cortex. J Neurosci 23:6557-6566. Medline

Yoshimura Y, Dantzker JL, Callaway EM (2005) Excitatory cortical neurons form fine-scale functional networks. Nature 433:868-873. CrossRef Medline

Zhang LI, Poo MM (2001) Electrical activity and development of neural circuits. Nat Neurosci 4:1207-1214. CrossRef Medline 